\title{
Quantitative Methods in Psychology
}

\begin{abstract}
A MEETING of the Royal Society was held on A March 24 to discuss the application of quantitative methods to certain problems in psychology. The discussion, which was on three different problems, was introduced by Dr. C. S. Myers, who pointed out that conscious experience can only be measured numerically in terms of the antecedent physical stimulus, the concomitant physiological activities, or the consequent changes in outward behaviour. If mathematical operations on psychological data are to be of psychological value, each step in such operations must be carefully studied so as to be assured that it is psychologically warranted and not merely of interest to the mathematician. The psychological whole being greater than the sum of its parts, and the nature of these parts being dependent on the whole, the limitations of psychological atomism and psychological mechanics must always be borne in mind. But even if factorial analysis, although mathematically possible, may have only a limited use in applied psychology, nevertheless occupational guidance and selection, as at present practised, are demonstrably of considerable value.
\end{abstract}

\section{Statistical Methods}

Prof. C. E. Spearman, who opened the first discussion, on recent developments of statistical method, described the development of factorial analysis as illustrated by his own work and that of Kelley, Thurstone and Holzinger. Prof. G. H. Thomson said that in his view vocational prediction entails the projection of a point, given by $n$ oblique co-ordinate axes called 'tests', on to a vector representing the 'occupation', the direction cosines of which are known but which is not in the $n$-space of the tests. The use of factors, whether oblique or orthogonal, merely involves reference of that point to a new set of co-ordinate axes called 'factors', instead of to the original test-scores-a procedure which, he argued, cannot define the point any better and may, unless great care be taken, define it worse. The chief value of the factor theory probably lies in its serving as a spur to further investigations and hypotheses. His belief is that the comparatively low rank to which so many matrices of mental correlation coefficients can be reduced indicates that the human mind is comparatively undifferentiated, protean and plastic, rather than that it is composed of separate faculties.

Prof. C. Burt regarded the factors isolated by analysis as merely convenient descriptive concepts which may, or may not, have a psychological basis. They need have no 'real existence', but serve much the same purposes as the lines of latitude or longitude upon a terrestrial map. In statistics the important measurement is not that of the clue and its consequence, but the measurement of the probability connecting the two. He referred to the great value of R. A. Fisher's formulæ for small samples, before the discovery of which it was considered that statistical methods could not be applied to less than 50 or 100 cases, and consequently the more detailed studies of the individual tended to give place to vast collections of inaccurate data. He also alluded to the easy comprehension and to the great value of matrix algebra for analytical purposes in statistical psychology - a method rarely utilized in the textbooks of pure statistics ; and to certain close analogies between recent developments in factor psychology and those in quantum mechanics.

A discussion of this subject followed by Drs. H. B. Heywood, J. O. Irwin and W. Stephenson.

\section{Industrial ACcidents ANd Sickness}

Prof. M. Greenwood introduced the next subjectindustrial accidents and sickness. He described how his early work at the Ministry of Munitions in 1918, on the distribution of accidents among those exposed to the same risk of them, led to later investigations conducted with the object of arriving at a statistical expression of the true and popular view that some people are 'all thumbs'. He was followed by Dr. May Smith, who gave an account of investigations conducted by the Industrial Health Research Board into the comparative absenteeism through sickness of those employed in selling, office work and manufacture. She indicated how dependent absenteeism also is on age, sex, incentives and management.

Mr. Eric Farmer and Mr. E. G. Chambers contributed to the discussion of this subject by describing their work on tests for the 'accident-prone', which provide with fair accuracy a prediction of accident rate for different groups of workers, although they are not sufficiently reliable in the case of any individual worker.

\section{Industrial Selection}

The last discussion, on psychological tests in industrial selection, was opened by a communication from Sir Frederick Marquis, who described the promising value of special tests for salesmanship introduced a year ago into Lewis's stores, but had found tests for general intelligence to be of no value. Mrs. Raphael pointed out that in another large stores the National Institute of Industrial Psychology had found no linear correlation between intelligence and retail salesmanship, too much intelligence being as undesirable a qualification as too little.

Wing Commander R. H. Stanbridge deseribed an experiment on the selection of aircraft apprentices with the aid of psychological tests. He found tests of intelligence and mechanical aptitude to be correlated with the passing-out results and to be definitely serviceable. Dr. W. G. Hiscock described the use of selection tests devised by the National Institute of Industrial Psychology for the Grangemouth branch of the Dye-stuffs Group of Imperial Chemical Industries, Ltd. Since 1934 all applicants for employment in the works have been submitted to these tests, as well as to a special medical examination, and not a single chemical process-worker has been discharged on the ground of inefficiency. Dr. Millais Culpin gave an account of an interesting investigation into the relation between 'nervousness' and the satisfactory and continued work of telegraph operators. 